ВЛИЯНИЕ ФАКТОРОВ НА ФОРМИРОВАНИЕ РЕСУРСОВ БАНКА

Перегудова Т.A. Студентка

Беляева А. $А$.

к.юр.н., доцент

Московский финансово-юридический университет МФЮА

\title{
INFLUENCE OF FACTORS ON THE FORMATION OF BANK RESOURCES
}

Аннотация. Банк формирует свою ресурсную базу под влиянием различных факторов, что определяет ее структуру и объем, а также впоследствии сказывается и на результате деятельности кредитной организации в целом. Поэтому в настоящее время в своей деятельности кредитные организации на постоянной основе проводят мониторинг поведения контрагентов и клиентов в процессе формирования ресурсной базы. В статье рассмотрены теоретические и практические аспекты вопроса - влияние факторов на формирование ресурсной базы кредитной организации.

Abstract. The Bank forms its resource base under the influence of various factors, which determines its structure and volume, and subsequently affects the result of the credit institution as a whole. Therefore, at present in its activities a credit institution on an ongoing basis monitor the behavior of counterparties and customers in the process of formation of the resource base. The article discusses the theoretical and practical aspects of the issue-the influence of factors on the formation of the resource base of a bank.

Ключевые слова: кредитная организация, ресурсы, факторы влияния, мониторинг, риски.

Keywords: bank, resources, influence factors, monitoring, risks.

Кредитная организация в рамках своей деятельности, с одной стороны осуществляет формирование ресурсной базы за счет привлечения свободных денежных средств физических и юридических лиц, а с другой стороны - размещает данные ресурсы от своего имени на условиях возвратности, срочности и платности. В результате ресурсы кредитной организации являются необходимым и активным элементом для осуществления банковской деятельности [6, с.88].

Проведенный анализ существующих подходов к пониманию «ресурсов банка» в научной литературе показал наличие большого множества трактовок их сущности. Это связано с различиями в степени изученности понятия и используемыми механизма исследования в разных странах, а также с тем, что берется за основу при формировании определения и какие факторы учитываются [9, с.89].

На Рисунке 1 собраны и визуализированы основные подходы к определению понятия «ресурсы банка».

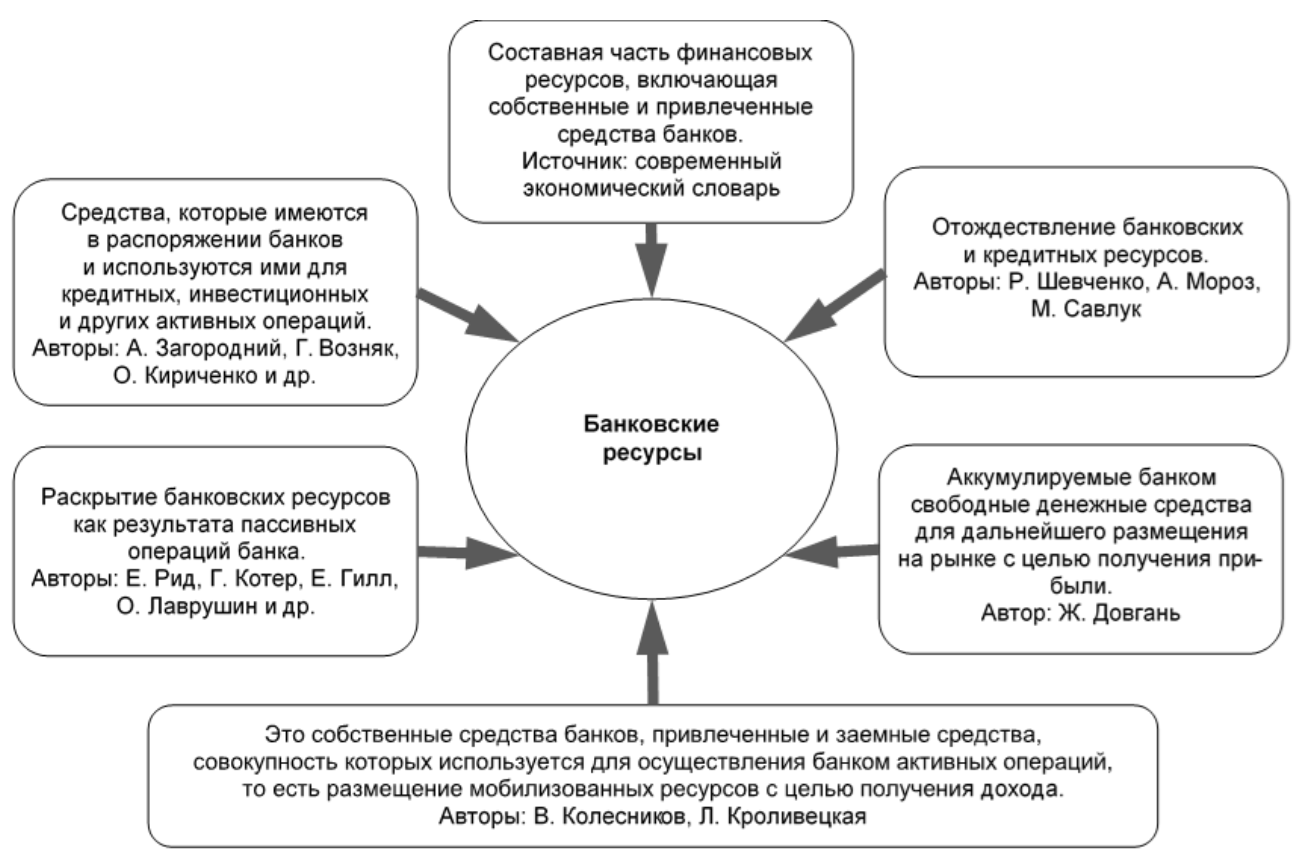


Опираясь на данные подходы определение можно представить следующим образом. Ресурсная база кредитной организации представляет собой совокупность таких элементов, как собственный капитал, привлеченные финансовые средства клиентов (юридических и физических лиц) и заемные средства, используемых для осуществления активных операций. При этом привлеченные средства могут быть сформированы за счет продажи долговых обязательств, а заемные приобретены на финансовом рынке.

Банк формирует свою ресурсную базу под влиянием различных факторов, что определяет ее структуру и объем, а также впоследствии сказывается и на результате деятельности кредитной организации в целом. Поэтому в настоящее время в своей деятельности кредитные организации на постоянной основе проводят мониторинг поведения контрагентов и клиентов в процессе формирования ресурсной базы.

На Рисунке 2 представлены факторы, которые оказывают влияние на формирование ресурсов банка.

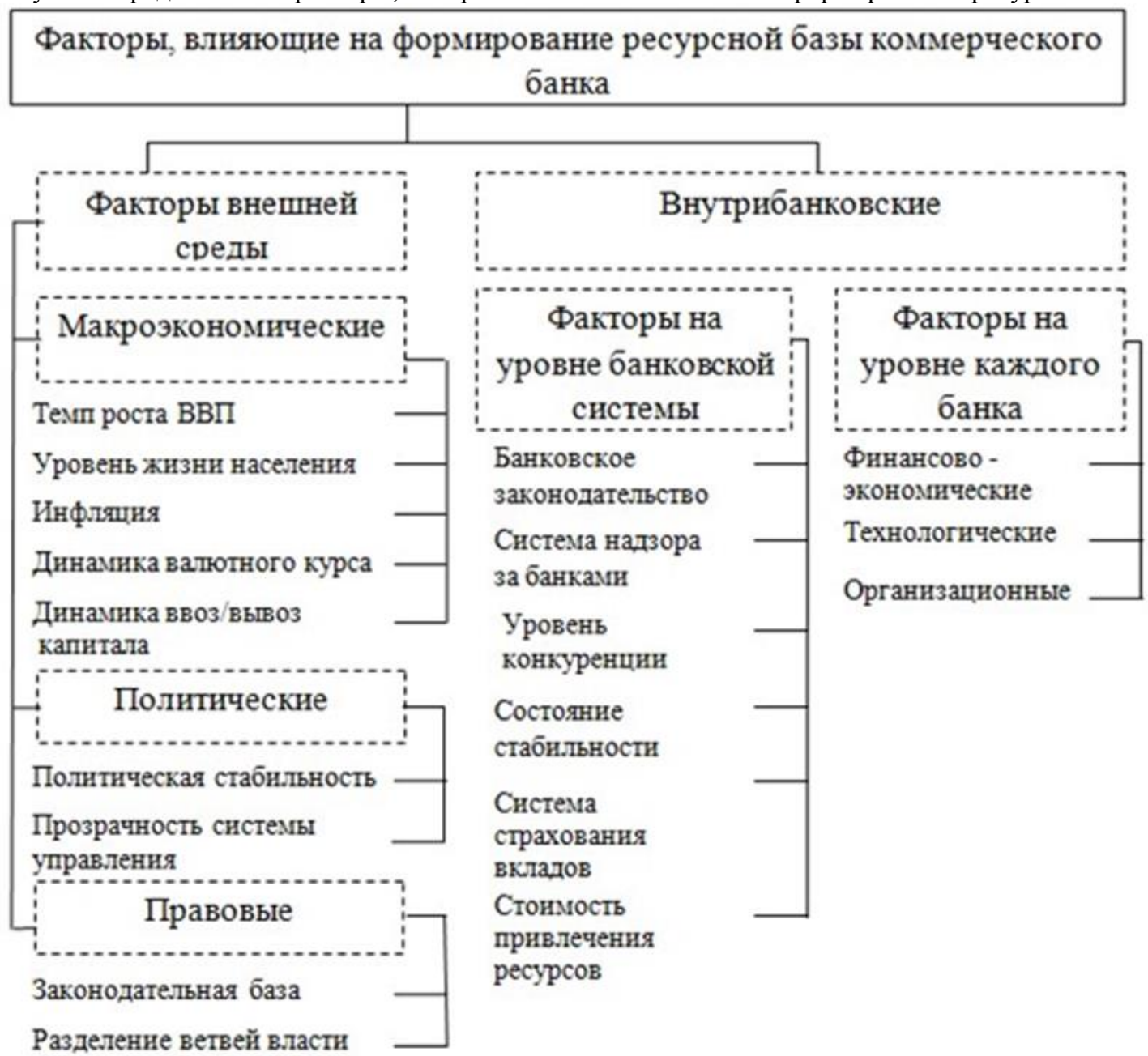

Рисунок 2 - Факторы, влияющие на формирование ресурсной базы коммерческого банка [12, с. 173]

Факторы, оказывающие влияние на пассивные операции банка, обычно группируются на внешние и внутренние.

Внешние факторы - это в первую очередь состояние экономики и политическая ситуация, на которые банк в рамках своей деятельности не может оказать влияние. В первую очень при формировании стратегии коммерческого банка учитываются макроэкономические (внешние) факторы, в том числе и их влияние на процесс привлечения ресурсов банка [14, с. 22].

Внутренние факторы - это состояние банковской системы и различные индивидуальные специфические особенности деятельности каждого конкретного банка [12, с.174]. К факторам уровня развития банковской системы страны относят такие, как актуальность законодательных норм, регулирующих банковскую сферу, уровень конкуренции на финансовом рынке, качество и эффективность системы страхования, и другие. Индивидуальные факторы специфичны для каждого банка, в также динамичны и меняются в связи с тем, что банк 
имеет возможность оказывать на них влияние в рамках своей деятельности. В первую очередь на формирование ресурсов банка оказывают влияние [14, с. 22].

Так как банк в своей деятельности формирования ресурсов банк подвержен различным рискам, то основными рисками, присущими деятельности ПАО «МИнБанк» в 2019 году, являлись кредитный риск и рыночные риски, а также в меньшей степени риск ликвидности и операционный риск.

В кредитной политике Банка определена необходимость диверсификации кредитных рисков, ведется контроль возможности возникновения крупных совокупных рисков, что позволяет не допускать нарушения установленных Банком России обязательных нормативов в части максимально допустимого размера кредитных рисков на одного или группу связанных заемщиков.

Топ-5 отраслевых концентраций рисков (нетто портфель за минусом резервов) представлена в Таблице 1.

Топ-5 отраслевых концентраций рисков (нетто портфель за минусом резервов), 2018-2019 гг.

\begin{tabular}{|c|c|c|}
\hline Показатель & 2018 & 2019 \\
\hline Операции с недвижимым имуществом, аренда & $16 \%$ & $14 \%$ \\
\hline Строительство & $14 \%$ & $11 \%$ \\
\hline Оптовая и розничная торговля & $14 \%$ & \\
\hline Сельское хозяйство & $12 \%$ & $21 \%$ \\
\hline Производство пищевых продуктов & $8 \%$ & - \\
\hline Производство электрооборудования/Производство транспортных средств & - & $8 \%$ \\
\hline Прочие & - & $7 \%$ \\
\hline
\end{tabular}

Источник: [13, С. 137]

В 2019 году в ходе работы Временной Администрации ключевой задачей являлась оценка качества активов и создание адекватных резервов. По итогам работы Банк сформировал резервы в сумме 146,7 млрд руб. в соответствии с РСБУ. Отметим, что в кредитной политике Банка определена необходимость диверсификации кредитных рисков, ведется контроль возможности возникновения крупных совокупных рисков, что позволяет не допускать нарушения установленных Банком России обязательных нормативов в части максимально допустимого размера кредитных рисков на одного или группу связанных заемщиков. Риск по неторговым позициям управляется и контролируется с использованием анализа риска процентной ставки.

В течение года на ежедневной основе проводился расчет величины рыночного риска по методике, определенной Положением Банка России от 03.12.2015 № 511-П (ред. от 27.02.2020) «О порядке расчета кредитными организациями величины рыночного риска» (Зарегистрировано в Минюсте России 28.12.2015 N 40328) [4], по ценным бумагам, которые Банк относит в торговый портфель (Фонд краткосрочных вложений). Полученные значения используются для расчета норматива достаточности собственных средств (капитала) Н1.0. Величина указанного риска по состоянию на 1 января 2020 года составила 9376191 тыс. руб. (на январь 2019 года 489259 тыс. руб.).

Наряду с расчетом совокупного рыночного риска по методике Банка России также используется оценка рыночного риска по методу Value-at-Risk (VAR) с доверительным уровнем 95\% [20].

Правление установило лимиты по позициям в иностранной валюте, основываясь на ограничениях Банка России. Позиции отслеживаются на ежедневной основе.

С целью ограничения риска ликвидности обеспечена доступность различных источников финансирования, управление активами осуществляется с учетом риска ликвидности и ежедневного мониторинга будущих денежных потоков. Этот процесс включает в себя оценку ожидаемых денежных потоков и наличие высококачественного обеспечения, которое при необходимости может быть использовано для получения дополнительного финансирования.

Банк владеет портфелем разнообразных активов, которые могут быть достаточно быстро реализованы за денежные средства в случае непредвиденного прекращения притока денежных средств. Оценка и управление ликвидностью осуществляется Банком в основном на независимой основе, опираясь на соотношения чистых ликвидных активов и обязательств клиентов.

Теперь отследим динамику изменения показателей ликвидности в течение 2017 - 2019 гг. (Таблица 2).

Основные показатели эффективности кредитования ПАО «МИнБанк»

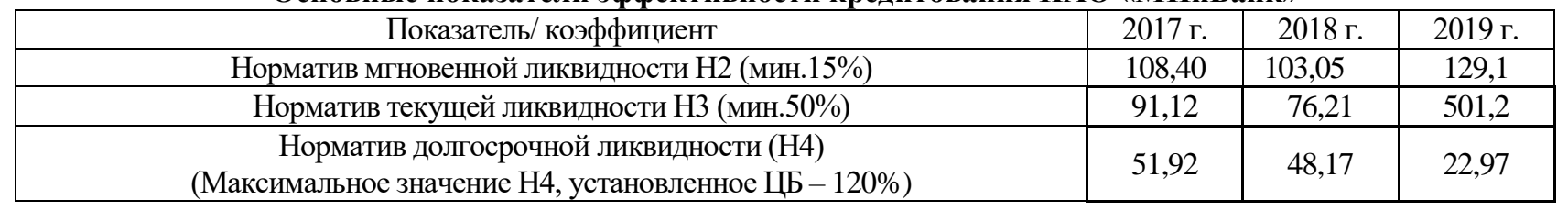


Источник: [составлено автором]

По медианному методу (отброс резких пиков): сумма норматива мгновенной ликвидности Н2 в течение исследуемого периода года довольно велика и имеет тенденцию к увеличению, сумма норматива текущей ликвидности Н3 неустойчива и имеет тенденцию к значительному росту, а экспертная надежность банка неустойчива и имеет тенденцию к значительному снижению [15, с. 471$]$.

Для обеспечения управления и контроля риска ликвидности, кроме ежедневного контроля вышеназванных нормативов, в Банке периодически проводится мониторинг ликвидной позиции на основе ГЭП-анализа, выполнения платежного календаря и стресстестирования.

Стресс-тестирование риска краткосрочной ликвидности проводится путем сравнения величины ликвидных активов, которые находятся под управлением Банка, и возможного оттока средств клиентов и банков на временном горизонте в 30 дней.

Стресс-тест, проведенный по состоянию на 1 января 2020 года, выявил избыток высоколиквидных активов на сумму 79,6 млрд руб. Данные результаты показывают, что Банк в этот период был в состоянии выдержать развитие стрессовых сценариев без допущения случаев несвоевременного выполнения своих обязательств перед клиентами.

Контроль риска краткосрочной ликвидности осуществляется также на основе расчета значения показателя краткосрочной ликвидности. Показатель краткосрочной ликвидности (ПКЛ) рассчитывается Банком на системной основе (ежемесячно) в соответствии с требованиями Положения Банка России от 04.07.2018 № 646-П (ред. от 30.06.2020) [3].

Таким образом, анализ финансовой деятельности и статистические данные за прошедший год кредитной организации ПАО «МИнБанк» свидетельствуют о наличии негативных тенденций, способных повлиять на финансовую устойчивость банка в перспективе.

Под руководством временной администрации были проведены комплексные меры по оптимизации организационной структуры, по расчету резервов под обесценение активов и расчету реального капитала, обеспечена деятельность Банка для дальнейшего развития и исполнения обязательств перед клиентами.

\section{ЛИТЕРАТУРА}

1. Федеральный закон «О Центральном банке Российской Федерации (Банке России)» от 10.07.2002 № 86Ф3 (в ред. от 20.07.2020) Собрание законодательства РФ. - 2002 г. - № 28. - ст. 2790.

2. Федеральный закон от 02.12.1990 № 395-1 (ред. от 27.12.2019) «О банках и банковской деятельности» (с изм. и доп., вступ. в силу с 14.06.2020) Ведомости съезда народных депутатов РСФСР. - 1990 г. - №27. - ст. 357.

3. Положение Банка России от 04.07.2018 № 646-П (ред. от 30.06.2020) «О методике определения собственных средств (капитала) кредитных организаций («Базель III»)» (Зарегистрировано в Минюсте России 10.09.2018 № 52122). [Электронный ресурc]. - URL: http://www.consultant.ru.

4. Положение Банка России от 03.12.2015 № 511-П (ред. от 27.02.2020) «О порядке расчета кредитными организациями величины рыночного риска» (Зарегистрировано в Минюсте России 28.12.2015 N 40328). [Электронный pecypc]. - URL: http://www.consultant.ru.

5. Бадыкова А.М. Управление ресурсами коммерческого банка // Начало в науке. Сборник материалов VI Международной научно-практической конференции школьников, студентов, магистрантов и аспирантов. В 2-х частях. Ответственные редакторы К.Е. Гришин, Н.А. Кузьминых. 2019. С. 138-140.

6. Банковское регулирование и надзор: учебник / И.В. Ларионова, С.Е. Дубова [и др]; Финансовый университет при Правительстве РФ. Москва: КНОРУС, 2019. 288 с.

7. Банковский надзор: учеб. пособие / Е.М. Дудник, П.П. Князев, М.Н. Клименко, Р.Ю. Луговцов. - Москва: Издательский дом Академии Естество знания, 2019. 445 с.

8. Бочарова Е.С. Банковские операции и их виды // Актуальные вопросы совершенствования бухгалтерского учета, статистики и налогообложения организации. Материалы VI международной научнопрактической конференции. 2017. С. 91-101.

9. Василенко В.В. Ресурсы коммерческого банка // Экономико-правовые перспективы развития общества, государства и потребительской кооперации. сборник научных статей II международной научно-практической интернет-конференции, посвященной 55 -летию университета. Под научной редакцией Ж. Ч. Коноваловой и Т. С. Алексеенко. 2019. С. 88-90.

10. Громова Л.С., Дубровина И.И. Особенности формирования привлеченных ресурсов коммерческого банка // Сборник студенческих работ кафедры «Финансы и банковское дело». Отв. ред. Я.Ю. Радюкова. Тамбов. 2019. C. 105-113.

11. Кузнецова В.В. Международный опыт пропорционального банковского регулирования // Электронный вестник. Серия: Государственное управление. 2018. № 69. С. 80-102.

12. Лисюткина И.А. Вопросы теории формирования и использования ресурсов российского коммерческого банка // Интеграция науки и практики: взгляд молодых ученых. Сборник научных трудов VI научно-практической 
конференции магистрантов и аспирантов. Редколлегия: Л.Ф. Попова [и др.]. 2020. С. 173-175.

13. Помулев А.А. Банковский сектор России: проблемы и перспективы в условиях новых вызовов // Теневая экономика. 2020. Том 4. № 3. С. 127-138.

14. Сергеева В.Ю. Формирование ресурсов коммерческого банка // Инновации в развитии научных и творческих направлений образовательного процесса. международный конкурс курсовых, научноисследовательских и выпускных квалификационных работ. Кемерово. - 2020. - С. 21-23.

15. Фомина Е.А., Камалов Р.К., Кутлубулатов И.И. Современные аспекты формирования финансовых ресурсов коммерческих банков // Евразийский юридический журнал. 2020. № 2 (141). С. 470-471.

16. Годовой отчет Публичного акционерного общества «Московский Индустриальный банк» за 2019 год. [Электронный pecypc]. - URL: https://www.minbank.ru (дата обращения: 10.11.2020).

17. Годовой отчет Публичного акционерного общества «Московский Индустриальный банк» за 2018 год. [Электронный pecypc]. - URL: https://www.minbank.ru (дата обращения: 10.11.2020).

18. Годовой отчет Публичного акционерного общества «Московский Индустриальный банк» за 2017 год. [Электронный pecypc]. - URL: https://www.minbank.ru (дата обращения: 10.11.2020).

19. Обзор банковского сектора Российской Федерации (Интернет-версия): Аналитические показатели. №206. декабрь 2019 г. Банк России. [Электронный ресурc]. - URL: http://www.cbr.ru/analytics/bank_system/obs_206.pdf (дата обращения: 29.10.2020).

20. ПАО «МИнБанк»: Официальный сайт. [Электронный ресурc]. - URL: https://www.minbank.ru (дата обращения: 09.11.2020). 